\title{
0 perfil da mídia no interior fluminense
}

\author{
Jaqueline da Silva Deolindo*
}

\begin{abstract}
Resumo
Este artigo apresenta um perfil da indústria de mídia em operação hoje no interior fluminense, enfatizando os aspectos geográficos e econômicos do setor. Parte da observação de que, assim como o interior do Estado do Rio de Janeiro registra distintos padrões de urbanização e desenvolvimento econômico, também a mídia em funcionamento nesse território oscila desde o nível mais artesanal até a oferta de serviços de notícia, informação e entretenimento de alto padrão técnico. Demonstramos brevemente, utilizando alguns exemplos, que quase sempre é possível relacionar os distintos padrões das mídias com os padrões das cidades em que estão sediadas. Defendemos, contudo, que em todos os casos as mídias locais e regionais tornam-se relevantes para o lugar quando realmente estão empenhadas e investem no atendimento das demandas de suas audiências por notícias, informações e pontos de vista.
\end{abstract}

Palavras-chave: Estado do Rio de Janeiro; Interior Fluminense; Localização da Indústria de Mídia; Jornalismo Local e Regional.

\begin{abstract}
This article presents a landscape of the media in operation today inside the State of Rio de Janeiro, emphasizing the geographic and economic aspects of this industry. Part of the observation that, like the countryside of Rio de Janeiro registers distinct patterns of urbanization and economic development, also the media operating in that territory ranges from handcrafted levels of news services, information and entertainment to the highest technician standard. The text demonstrates briefly, using some examples, that almost always is possible to relate the different patterns of media with the standards of the cities in which they are based on. However, we argue that in all cases the local and regional media become relevant when they really are committed and invest to provide the demands of their audiences for news, information and points of views.
\end{abstract}

Keywords: Rio de Janeiro State; Fluminense Countryside; Location of Media Industry; Local and Regional Journalism.

\footnotetext{
* Jornalista pelo Centro Universitário Fluminense (Campos/RJ), mestre e doutoranda em Comunicação pelo Programa de Pós-Graduação em Comunicação da UERJ. E-mail: jacquelinedeolindo@gmail.com
} 


\section{Introdução}

Mídia, para efeitos deste artigo, é o sistema formado por firmas especializadas na produção de notícia, informação e entretenimento para o grande público. Aqui, enfocamos mais especificamente o conjunto dos jornais, sites de notícias, revistas, emissoras de rádio e TV. ${ }^{1}$ São empresas que desempenham influência importante em quase todos os setores da sociedade ao exercerem, entre outras, a função de mediação, agendamento e formação da opinião pública, além de interferirem significativamente nos campos da política e da economia. Nesse último setor, a participação dos negócios de mídia é crescente, e incluindo produção de conteúdo, venda de produtos e dispositivos, desenvolvimento de plataformas e fornecimento de serviços, já esbarra em $6 \%$ do PIB mundial. ${ }^{2}$

Trata-se de um sistema produtivo de bens e serviços cujo elevado grau de especialização pode ser identificado, entre outras evidências, 1) entre os profissionais da área, com seus processos criativos, individuais ou em grupo; 2) na complexa organização que as empresas de mídia podem configurar dentro do próprio ambiente institucional ou sobre o território, o que vai implicar diretamente a adoção de tecnologia, a produção e a logística de distribuição; 3) em sua relação de dependência, influência e complementaridade com outras organizações e instituições, e nos aspectos culturais, técnicos e socioeconômicos do lugar em que a produção da mídia acontece.

A cadeia de produção da mídia, em geral, é dominada por um pequeno grupo de cidades e se acha concentrada em determinadas regiões que dispõem de a) diversos elementos que historicamente favoreceram um contexto de produção cultural, intelectual e artística de referência e b) maior arrojo econômico, típico dos grandes centros urbanos onde essas empresas estão sediadas.

Esses lugares são vetores tradicionais de difusão de bens simbólicos, estendendo sua influência sobre outros espaços. Observamos, entretanto, que, devido ao descentramento das atividades produtivas por que tem passado o país nas últimas décadas e à virtualização dos mercados consumidores, outros espaços de produção de mídia com relativa representatividade têm emergido em regiões com um aparato técnico e científico favorável.

Mas quais são as principais características dos negócios de mídia no Brasil?

O país, sob diversos aspectos, segue a tendência mundial. Aqui, a televisão é o meio de comunicação de maior alcance territorial e de público, seguida do rádio (no que se refere à receita publicitária, a TV concentra a maior parte dos investimentos dos anunciantes, seguida dos impressos). O segmento de mídia impressa, que inclui jornais e revistas de todas as periodicidades, tem uma penetração menor entre os diversos públicos, mas as versões on-line desses meios, além dos portais de notícia em operação exclusivamente na web, têm ganhado cada vez mais adesão em todas as regiões do país. As redes sociais das mídias jornalísticas crescem em importância nesse cenário ao funcionarem como um meio veloz para distribuição de conteúdo e chamariz para as plataformas mais tradicionais. ${ }^{3}$

1 Eventualmente, ao longo do texto, nos referimos a indústrias de mídia, empresas jornalísticas, meios de comunicação, mídia ou empresas de mídia como sinônimos. Em outros contextos, podemos incluir ao grupo das indústrias de mídia a produção de filmes, música e multimídia, produtoras independentes de conteúdo noticioso, o comércio de publicação, editoras de revistas, agências de design e publicidade e desenvolvedores de softwares e plataformas que atendem a esse mercado específico.

20 dado faz parte do quadro da indústria de mídia apresentado por Eli Noam na Conferência Mundial de Economia e Gestão de Mídia, realizada na Universidade do Estado do Rio de Janeiro em maio de 2014. Ver referências.

3 Para detalhes sobre o setor, conferir, por exemplo, ANJ (2014), IVC (2013), EBC (2013), ANCINE (2011), ABTA (2013) e ABERT (2013). 
A mídia brasileira é formada por empresas de todos os portes que operam na produção e circulação de conteúdos em escalas diversas, do local ao internacional. No país, o setor cresceu mais amplamente na região Sudeste, polarizadora da economia brasileira, com destaque para as cidades do Rio de Janeiro e São Paulo. Também é a partir desses lugares que ocorre o monopólio da produção, que resulta no crescimento de verdadeiros complexos industriais que enrijecem as barreiras à entrada de novos empreendimentos e limitam as opções das audiências a um cardápio de textos cujos vieses são controlados pela ideologia dos conglomerados. No entanto, desde os anos 1990, ainda que as maiores empresas mantenham seu centro de comando nas duas metrópoles citadas e também em algumas outras capitais estaduais, ocorre uma intensificação da regionalização das indústrias de mídia, com a intenção de atender demandas mais localizadas. ${ }^{4}$ Vale ressaltar, ainda assim, que operar mídia em grandes cidades e operar no interior, independente da região em que isso acontece, são processos sensivelmente diferentes.

Isto posto, e tendo como pano de fundo a interiorização dos negócios de mídia, traçamos neste texto um perfil da mídia fluminense tendo como foco principal jornais impressos, sites de notícias, rádio e TV de abrangência local e regional localizados fora da Região Metropolitana do Rio de Janeiro. Levamos em consideração principalmente as dimensões econômica e organizacional dos negócios e as especificidades do território em que operam. ${ }^{5}$

Em um primeiro momento, procuramos relembrar aspectos gerais do interior do Estado do Rio, procurando reunir informações que ajudem a compreender sua configuração espacial e sua realidade socioeconômica. Em seguida, procuramos relacionar os aspectos geoeconômicos do território fluminense ao desenvolvimento de suas empresas de mídia, apresentando dados obtidos durante nossa pesquisa de campo que nos permitam desenhar um perfil desse mercado. Por fim, procedemos às nossas reflexões sobre a produção jornalística no interior, a função e o valor do jornalismo local e regional para o seu público.

\section{1 - O território fluminense}

O Estado do Rio de Janeiro, que conta com mais de 16,4 milhões de habitantes (IBGE, 2014, on-line), é um dos menores estados da Federação, mas um dos que registram as maiores taxas de densidade populacional. Oficialmente dividido em oito regiões de governo (Norte, Noroeste, Serrana, Baixadas Litorâneas, Metropolitana, Médio Paraíba, Centro Sul e Costa Verde), esse território é composto por 92 cidades - 21 na Região Metropolitana ${ }^{6}$ e 71 na área chamada interior do Estado. Uma das características demográficas mais marcantes dessa unidade federativa é o predomínio da população urbana sobre a rural - 96\% contra 4\% - e uma concentração massiva de residentes na Região Metropolitana (75,6\%) (IBGE, 2014, on-line, op. cit.).

\footnotetext{
4 Reunimos em dois trabalhos recentes dados gerais sobre o número de empresas de mídia em operação no Brasil, sua localização e indicadores de desempenho econômico. Ver em Deolindo (2014b) e Deolindo \& Moreira (2013), nas referências.

50 foco no interior está relacionado à nossa tese, a ser defendida até agosto de 2016. Ela aborda a espacialidade e a economia da mídia do interior fluminense. Inclui um inventário das mídias jornalísticas em funcionamento nesse território, uma análise mais detalhada da estrutura, organização e funcionamento dos jornais diários e sites de notícias e entrevistas com gestores. Todos os dados aqui apresentados sobre a mídia no interior do Estado do Rio de Janeiro fazem parte da pesquisa de campo, ora em andamento. A pesquisa de campo inclui o mapeamento de todos os meios de comunicação jornalísticos do referido território (emissoras de TV, rádio, impressos em geral e portais de jornalismo on-line) e entrevistas com 31 gestores de jornais diários e sites de notícias. A primeira etapa do trabalho (mapeamento) já foi concluída e está em constante atualização. A segunda, com base em uma pesquisa exploratória realizada com 13 gestores de mídia de diversas regiões do interior do Estado e em outra feita com membros da audiência, já está em andamento. Os dados que apresentaremos na segunda seção deste artigo se referem a essas incursões de base.

6 Compõem a Região Metropolitana do Rio, as seguintes cidades, segundo o mapa mais recente: Rio de Janeiro, Belford Roxo, Duque de Caxias, Guapimirim, Itaboraí, Japeri, Magé, Maricá, Mesquita, Nilópolis, Niterói, Nova Iguaçu, Paracambi, Queimados, São Gonçalo, São João de Meriti, Seropédica, Tanguá, Itaguaí, Rio Bonito e Cachoeiras de Macacu (FUNDAÇÃ̃O CEPERJ, 2014c, online).
} 
No que se refere a sua economia, registra-se a polarização intensiva da Região Metropolitana com relação às demais regiões do estado. Ainda que a referida área encerre grandes problemas e contradições, de um modo geral, é ela que

\begin{abstract}
concentra capital, infraestrutura e força de trabalho. Aí se encontra a maior parte das indústrias do Estado, formando um parque industrial bastante diversificado. Reúne também serviços altamente especializados nos setores financeiro, comercial, educacional e de saúde, assim como órgãos e instituições públicas, entre outros. (FUNDAÇÃO CEPERJ, 2014b, on-line)
\end{abstract}

Graças a essa primazia, a Região Metropolitana lidera a participação no PIB Estadual, com 62,62\% em 2011, com destaque para o posicionamento da cidade do Rio (45,3\%); de Duque de Caxias (5,8\%) e de Niterói (3,1\%). (FUNDAÇÃO CEPERJ, 2014a, on-line)

Cremos ser importante grifar que a formação socioeconômica da Região Metropolitana é resultado direto do papel exercido pela capital do estado ao longo de mais de dois séculos. A cidade do Rio de Janeiro é, historicamente, uma das mais favorecidas cultural, política e economicamente entre todas as demais cidades do país: cidade imperial, portuária, integrante da rota artística e comercial internacional, pioneira na adoção de diversos avanços urbanísticos e tecnológicos, dotada de indústrias e de uma singular infraestrutura, o Rio sempre se destacou por sua "vocação cosmopolita”, por seu caráter de "microcosmo do Brasil” e por ser "palco privilegiado da experiência moderna brasileira”, como lembra Fusco (2008:17).

Já o interior do estado apresenta uma realidade bastante diferente, marcada por distanciamentos, defasagens e discrepâncias com relação à capital e à Região Metropolitana, em diversos aspectos. Esse descompasso, na visão do autor citado, teria ocorrido por dois motivos principais, intimamente relacionados: porque a capital do estado e a Região Metropolitana como um todo nunca desempenharam um papel articulador com o restante do território fluminense e porque as cidades do interior, de um modo geral, não se constituíram como centros regionais produtores e disseminadores dinâmicos (Fusco, 2008).

Fato é que o interior do Estado participa com os demais 37,38\% do PIB estadual, mas esse índice é determinado principalmente pelo desempenho de Campos dos Goytacazes (8,0\%) e de Macaé (2,7\%), por causa da indústria do petróleo (FUNDAÇÃO CEPERJ, 2014a). Esses números indicam que a polarização verificada na Região Metropolitana do Estado do Rio, notadamente pela capital, com relação a outras cidades do país e principalmente com relação a outras cidades do estado, ocorre também na escala regional, ainda que por motivos específicos.

O interior fluminense tem entre suas principais características os díspares graus de urbanidade, a distribuição heterogênea dos recursos naturais e a polaridade econômicofinanceira. Por exemplo, ao mesmo tempo em que há no interior importantes centros regionais, como Macaé, e capitais regionais do porte de Barra Mansa-Volta Redonda e Campos dos Goytacazes, com população variando entre 122 mil habitantes e 480 mil habitantes (IBGE, 2008; 2014), o interior do estado abriga em sua maior parte municípios de pequeno porte (com população inferior a 50 mil habitantes), muitos dos quais classificados como rurais (8) ou em transição para urbanos (21) (Ribeiro e Cavalcanti, 2012).

Há, sem dúvida, centros mais proeminentes, como os polos de atividade altamente especializada localizados no Norte, no Centro-Sul, na Costa Verde e no Médio Paraíba. No entanto, não raro há também cidades que registram atraso tecnológico, baixo dinamismo e economia relativamente atrasada, como várias das regiões Noroeste, Serrana e das Baixadas Litorâneas (Silva, 2009). Apesar da existência, ali, de algumas atividades importantes, como o ramo de produção de hortifrutigranjeiros, de leite, de confecções e de turismo, de grande 
importância local, a economia desses lugares registra impacto inexpressivo sobre o PIB estadual. Por outro lado, o interior do estado, que já teve forte presença do investimento estatal, hoje se destaca do padrão de desenvolvimento do interior brasileiro em geral pela forte aplicação do capital privado, inclusive estrangeiro. ${ }^{7}$

Como argumenta Duarte (2009, on-line),

Após um longo período de verdadeiro marasmo econômico, que durou cerca de trinta anos, uma série de fatores tem contribuído para melhorar as perspectivas de crescimento econômico do estado, atraindo importantes investimentos, inclusive os industriais, cuja decadência no estado era marcante. Essa recente retomada do dinamismo econômico estadual, inseparável da melhoria do quadro econômico nacional, abre novas perspectivas de reorganização do território fluminense, cujos desdobramentos ainda não são totalmente nítidos. Eles dependerão, em grande medida, das políticas públicas e dos investimentos em infraestrutura, que constituem uma das grandes carências do espaço econômico estadual. Eles são essenciais para incentivar o crescimento econômico e ampliar a difusão espacial e social de seus benefícios.

O Estado do Rio de Janeiro, entretanto, encerra muitas outras contradições e complexidades importantes. Neste artigo, interessa-nos, sobretudo, abordar alguns aspectos principais da produção midiática, cujos padrões, a nosso ver, relacionam-se intimamente com as características geoeconômicas de cada região.

\section{2 - A mídia no Estado do Rio de Janeiro - metrópole e interior}

Como já citamos, no Brasil, as indústrias de mídia estão concentradas em espaços que vêm desenvolvendo há séculos um contexto de produção cultural, intelectual e artística de referência, espaços estes com economia e características urbanas mais desenvolvidas. Não por acaso, como também já mencionamos, a Região Sudeste concentra a maior parte dos meios de comunicação do país, com liderança de São Paulo seguida do Rio de Janeiro.

Mas, mesmo nessas unidades federativas, onde há grandes índices de produção midiática, são as cidades grandes e médias que detêm os maiores índices de produção de notícias e informação. São cidades que se destacam na rede urbana por sua real ou relativa condição de proeminência, dinamismo, autonomia, desenvolvimento e centralidade, garantidos pela presença de órgãos oficiais administrativos e decisórios, instalação de sedes e filiais de empresas e oferta de uma maior e mais especializada variedade de equipamentos e serviços (entre eles, os de mídia) (IBGE, 2008). Por outro lado, há cidades interioranas que não têm sequer uma emissora de rádio comunitária.

Vejamos como esse fenômeno se reproduz no Estado do Rio de Janeiro. Na Região Metropolitana, é a capital que se destaca absoluta por concentrar a maior parte dos meios de comunicação da referida área e ser sede de algumas das maiores e mais importantes empresas de mídia do Brasil, como as pertencentes às Organizações Globo. É a típica "cidade midiática global” a que se refere Moreira (2013), lugar por excelência das indústrias e dos negócios de mídia.

As cidades midiáticas globais que surgiram na década de 1990 em alguns países significaram formas de representação do espaço urbano como referência midiático-cultural, operando em diferentes níveis geográficos. Nascem vinculadas à cultura urbana, incorporando as características intermediárias entre os modos de vida rural e urbano; mostram a diversidade de estilos de vida dos habitantes dos centros urbanos e criam ambientes de serviço e de entretenimento que atraem modelos diversos de desenvolvimento econômico. As principais características das cidades midiáticas globais dizem respeito ao índice de produção, à oferta de serviços e ao

7 Uma abordagem das regiões de governo de acordo com sua vocação econômica não se mostra relevante para os propósitos deste artigo porque, neste momento, não interfere em nossa análise. Então, para não corrermos o risco de simplificar tal descrição para torná-la mera citação, sugerimos a leitura do texto "Estado do Rio de Janeiro - Regiões de Governo", da Fundação Ceperj, que faz uma apresentação mais minuciosa da geoeconomia fluminense. Ver referências. 
desenvolvimento de projetos de mídia para distribuição internacional. As cidades midiáticas globais abrangem a indústria midiática como um todo, desde impressos e produtos audiovisuais até editoras e mídia digital online, entre outras. (Moreira, 2013:15)

Já nas 71 cidades que compõem o interior do Estado do Rio, território que é foco do nosso estudo, existem em torno de 500 meios de comunicação de caráter jornalístico em operação, com prevalência de sites de notícias e blogs noticiosos/opinativos (210), seguidos das estações de rádio comerciais e comunitárias (160), dos impressos em geral (125) e das emissoras de TV abertas e por assinatura (17). ${ }^{8}$

Os números incluem um grupo restrito de empresas, produtos e serviços de alto padrão, como nos casos de afiliadas e sucursais de emissoras de TV abertas, de alguns portais de notícias e de jornais diários de maior porte; outro grupo mais generoso de empresas de padrão intermediário e um terceiro grupo ainda mais numeroso de iniciativas próximas do que Milton Santos chamou de "artesanato de imprensa” (Santos, 1959 [2007]). Observamos que em diversos casos os distintos padrões das mídias são correspondentes ou coincidem com as características socioeconômicas das cidades em que estão sediadas. Essas diferenças também se observam em outros aspectos, como na distribuição espacial das empresas de mídia sobre o território e na estrutura financeira das firmas, o que, consequentemente, poderá refletir no perfil, na independência, no alcance, na função e na relevância de seu conteúdo.

GRÁFICO 1

Número de mídias em operação no interior fluminense por plataforma

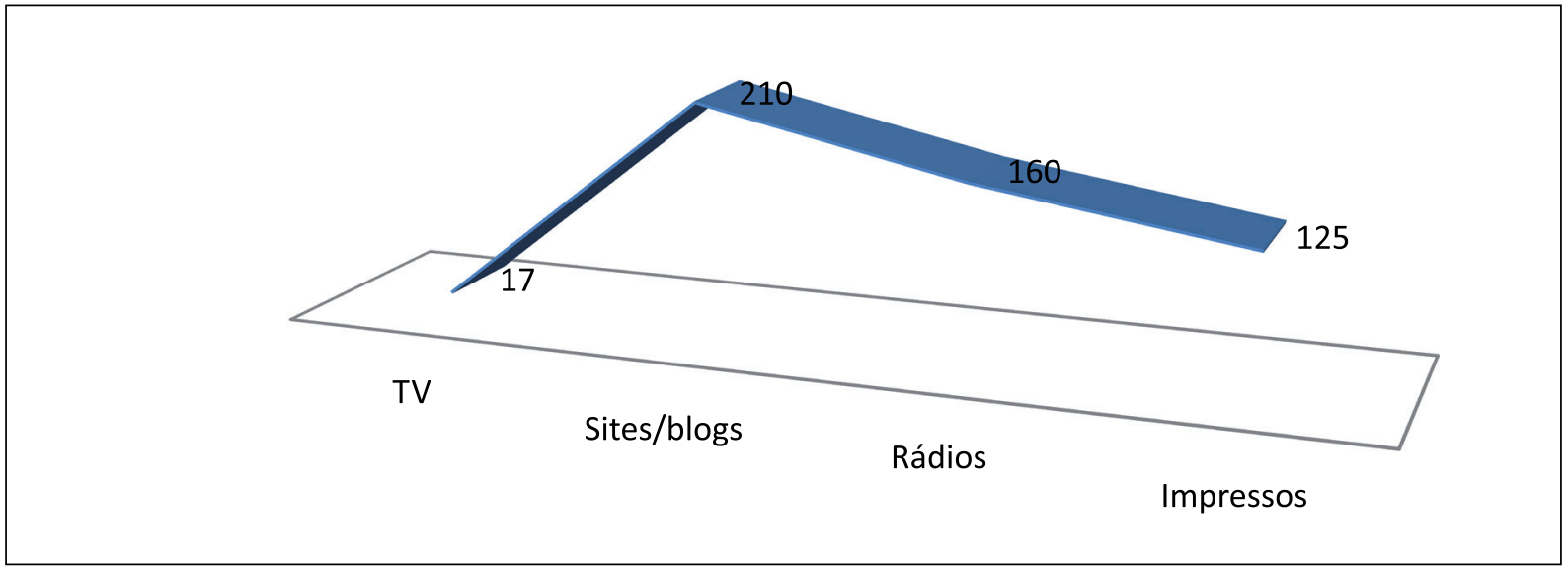

Fonte: Elaboração própria a partir da pesquisa de campo, disponível também em Deolindo (2013) e em Moreira \& Deolindo (2013).

A distribuição espacial dessas mídias parece definida por três determinantes, quase sempre relacionados: a urbanização, a economia e a cultura, visto que as cidades com maior número de empresas de mídia em sólido funcionamento são as que 1) registram grande densidade populacional, organização, condições e modos de vida típicos da cidade, 2) uma economia mais dinâmica e pujante, com mercado consumidor consolidado ou emergente e/ ou 3) uma tradição na produção e circulação de produtos jornalísticos.

No entanto, devido à democratização do acesso à internet e a diversas plataformas e dispositivos tecnológicos, observamos a emergência de um quarto definir: a escassez, visto que muitas cidades e regiões onde não há empresas de mídia ou o setor é insipiente, jornalistas e cidadãos não especializados na área de comunicação têm lançado portais, sites,

80 número de mídias varia em cada atualização do mapeamento devido ao fechamento e abertura de novos empreendimentos entre um levantamento e outro. Isso ocorre principalmente entre os pequenos sites de notícias e os impressos de periodicidade semanal a bimensal, quando estes dependem da arrecadação da verba publicitária para fazerem circular novas edições. 
blogs e perfil em redes sociais com a intenção de reunir ou produzir notícias locais e, assim, criar um espaço para tratar das questões que são importantes para o lugar. Nem sempre essas mídias on-line são registradas, e boa parte delas ou não opera visando lucro ou seus donos trabalham com diversas limitações para se manterem no mercado nos primeiros anos de funcionamento.

O Mapa 1 representa a proporção de mídias jornalísticas no território fluminense por região de governo e, para além da Região Metropolitana, aponta uma concentração significativa de meios de comunicação na região Norte Fluminense, com a contribuição decisiva primeiro de Campos dos Goytacazes e, depois, de Macaé, devido ao grande número de mídias em funcionamento nas duas cidades. Campos, a propósito, é a cidade do interior fluminense com o maior número de meios de comunicação jornalísticos.

MAPA 1

Distribuição das mídias pelas regiões de governo

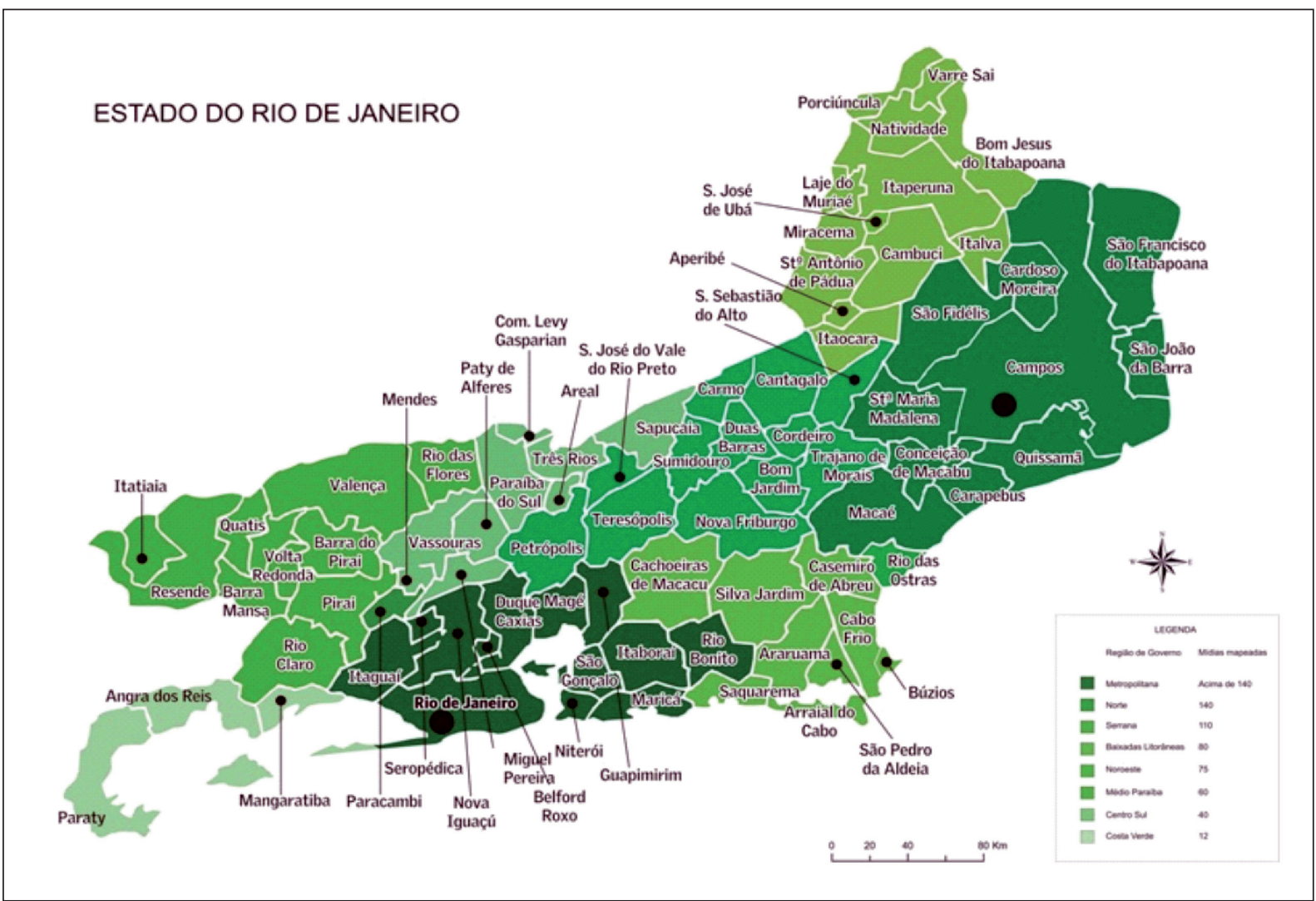

Fonte: Elaboração própria a partir da pesquisa de campo sobre base cartográfica do IBGE.

Em uma tentativa de descrever as regiões de governo de acordo com as empresas de mídia que sediam, podemos dizer que

1) as regiões que têm mais mídias têm também mais mídias diárias, o que indica que, em geral, essas regióes têm um padrão midiático de mais alta ordem devido à estrutura exigida por tais empresas;

2) as mídias diárias em funcionamento nessas regiões, ou seja, jornais diários, portais de notícias com atualização dinâmica, emissoras de rádio e TV, têm um padrão correspondente à gradação de cor do mapa, ou seja, ainda que sejam todos serviços de mais alta ordem, sua especialização e qualificação também podem ser classificadas segundo uma hierarquia que cresce ou decresce com a paleta.

Entretanto, uma abordagem mais eficiente, a nosso ver, deve considerar o desempenho 
de determinadas cidades que incontestavelmente se destacam por sediarem firmas cujo padrão de produção de mídia é mais elevado ou por reunirem um grande número de empreendimentos do setor. Significa dizer que, quando se trata de empresas de mídia, podese falar de uma geoeconomia mais localizada devido à produção ser altamente concentrada.

Por exemplo, se considerarmos apenas as 14 cidades consideradas polos e subpolos regionais (FUNDAÇÃO CEPERJ, 2014b, on-line), temos que mais de 60\% das mídias do interior fluminense estão nessas localidades centrais, a saber, em Itaperuna, Santo Antônio de Pádua, Bom Jesus do Itabapoana, Campos dos Goytacazes, Macaé, Nova Friburgo, Petrópolis, Resende, Volta Redonda, Barra Mansa, Paraty, Angra dos Reis, Cabo Frio e Três Rios. ${ }^{9}$ Essas cidades não apenas concentram a maior parte dos meios de comunicação do interior do Estado como também os maiores empreendimentos, os investimentos mais sólidos em termos empresariais e os mercados mais abrangentes, considerando o alcance das audiências.

Os meios de comunicação sediados nas cidades citadas acima privilegiam os assuntos locais e eventualmente produzem notícias sobre as cidades vizinhas que não dispõem dos próprios equipamentos de mídia ou cujas mídias têm produção pouco expressiva. É justamente nesses casos que pode haver a referida demanda por notícias locais, que, não satisfeita por operadoras das plataformas tradicionais, vem sendo atendida por iniciativas tornadas possíveis graças às novas tecnologias da comunicação e informação.

Alguns exemplos são fornecidos pelas cidades de São João da Barra, no Norte Fluminense; São Pedro da Aldeia, na região dos Lagos, e Cantagalo, na região Serrana. Nessas cidades, os impressos existentes são semanais ou de periodicidade mais espaçada e as rádios são de banda FM, com ênfase em programação musical. Ainda que São João Barra faça limite com Campos dos Goytacazes, que tem um forte sistema de mídia e jornalismo diário funcionando em diversas plataformas, como temos mencionado, sua situação não difere substancialmente das demais cidades mencionadas: todas têm registrado o lançamento de sites de notícias que tentam cumprir aquele objetivo que nem as mídias ali existentes nem as do entorno conseguem ou pretendem: apreender o cotidiano local pelo movimento. ${ }^{10}$

Uma análise mais detalhada do mercado de mídia do interior fluminense, tanto o tradicional quanto o emergente, mostra que o interior do Estado do Rio possui 14 jornais diários impressos de circulação paga, em funcionamento em Itaperuna, Campos, Macaé, Cabo Frio, Nova Friburgo, Petrópolis, Teresópolis, Barra Mansa, Três Rios e Volta Redonda. ${ }^{11}$ É interessante notar que todos os diários impressos do interior fluminense são editados em cidades com alto grau de urbanização (RIBEIRO; CAVALCANTI, 2012). Em sua maioria são empresas cujos quadros têm entre 5 e 50 pessoas, mas o setor também inclui empresas de maior porte, com quadros compostos por 60 a 120 pessoas. As tiragens variam entre 5 mil e 12 mil exemplares por dia e o preço de capa varia entre $\mathrm{R} \$ 0,50$ e $\mathrm{R} \$ 3$, dependendo do jornal e do dia da semana. A maioria dos gestores considera a mídia de abrangência essencialmente local. Todos os jornais diários têm site na internet. ${ }^{12}$

9 Interessante registrar que Campos dos Goytacazes, no Norte Fluminense, e Petrópolis, na região Serrana, têm uma tradição centenária de diários impressos.

10 Em São João da Barra, estavam em funcionamento na data de finalização deste artigo, 31 de outubro de 2014, os sites http://portalozk.com/dlf/; http://www.quotidiano.com.br/; http://sjbonline.com.br/ e http://www.parahybano.com.br/site/. Em São Pedro da Aldeia, entre outros blogs, o http:// noticiadesaopedrodaaldeia.blogspot.com.br, e em Cantagalo, http://aserra.com.br/.

11 Campos, Macaé e Petrópolis têm cada uma dois jornais diários em funcionamento atualmente. As demais cidades, um jornal diário cada, entre outras mídias.

12 Alguns jornais diários já começam a desenvolver estratégias para que seus sites não sejam concorrentes dentro da própria casa. Podemos citar, por exemplo, a Tribuna de Petrópolis, que permite que apenas assinantes acessem o site do jornal, e o Diário do Noroeste, em Itaperuna, que não disponibiliza as imagens da versão impressa nem as notícias do próprio dia em seu site. 
Em geral, os jornais diários têm uma gestão consolidada. Mais da metade faz parte de conglomerados locais e regionais e metade são empresas familiares. Com raras exceções, os diretores calculam que cerca de $70 \%$ da receita têm como fonte os anunciantes de empresas privadas, vendas avulsas e assinaturas; $30 \%$ seria a participação dos governos municipais, estadual e federal no faturamento, através de anúncios, editais e publicações oficiais. No entanto, a maior parte dos impressos no interior do estado tem periodicidade semanal a mensal e é notória a dependência dos poderes públicos para sua manutenção.

MAPA 2

Cidades do interior fluminense com jornais diários

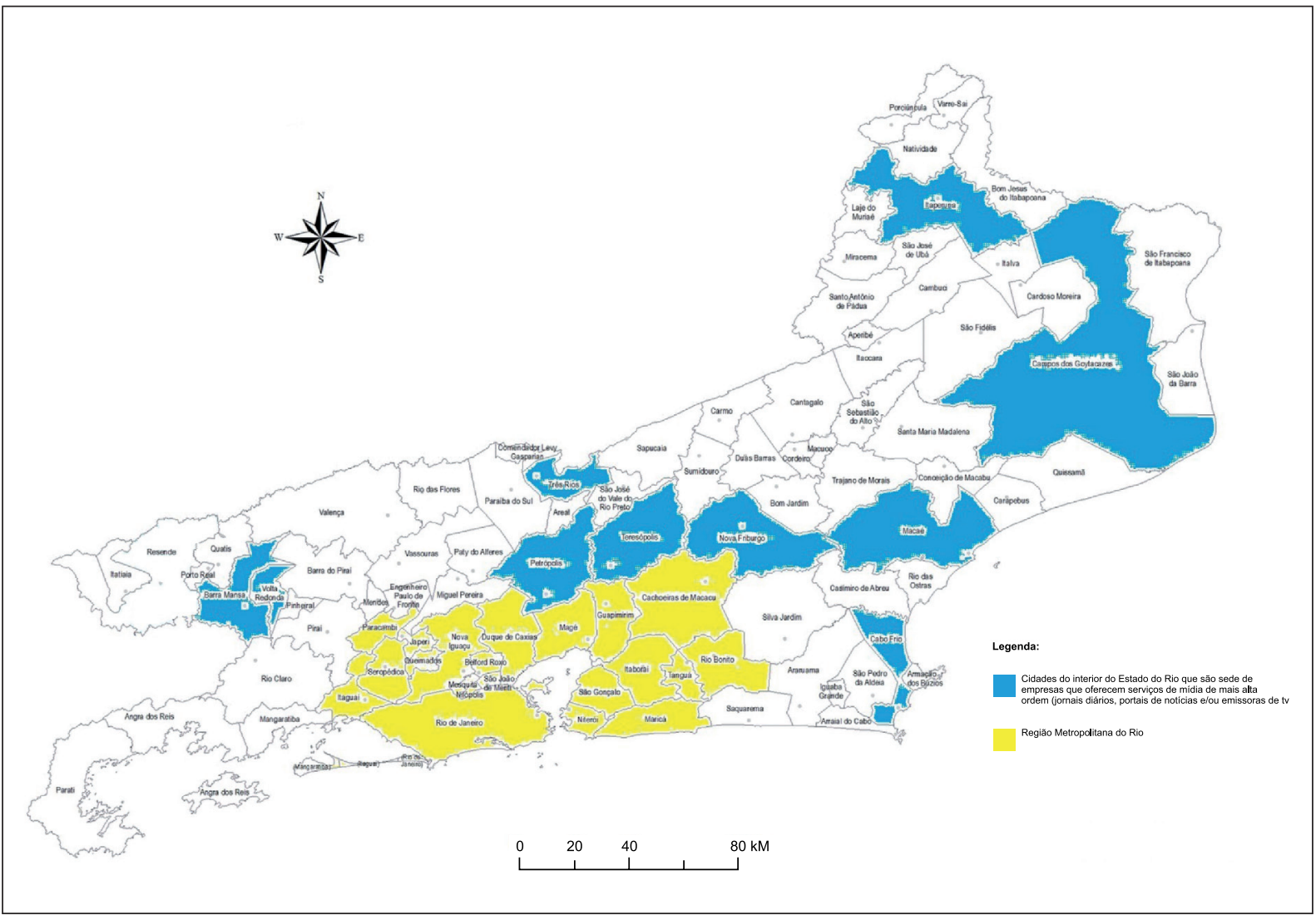

Fonte: Elaboração própria a partir da pesquisa de campo sobre base cartográfica do IBGE.

Sobre as TVs, encontramos emissoras ou sucursais de afiliadas de TV aberta em Campos, Macaé, Cabo Frio, Nova Friburgo, Petrópolis, Angra dos Reis, Barra Mansa, Volta Redonda, Resende e Três Rios. O caráter regional dessas mídias permite que elas alcancem anunciantes e públicos de áreas muito amplas. A participação das TVs a cabo no mercado também deve ser considerada. Além da maior parte das cidades já citadas neste parágrafo, Itaperuna e Teresópolis também contam com estúdio e escritório locais de produtoras de conteúdo para TV por assinatura. Outro serviço é a webTV, que produz e veicula, entre esparsas notícias locais e regionais, vídeos dos anunciantes e seus produtos, além de disponibilizar o material para o site www.youtube.com Trata-se de uma produção bastante elementar. Algumas cidades do interior já registraram experiências com esse tipo de mídia, entre elas Santo Antônio de Pádua, Araruama e Maricá.

Já as emissoras de rádio aparecem em número expressivo no interior fluminense e desempenham um papel importante de informação e coesão social nas cidades em que estão instaladas e também no entorno. Em sua maioria são empresas autônomas, mas encontramos também emissoras ligadas a grandes cadeias de rádio, como sucursais da rádio O Globo, 
em Macaé; da Band FM, em Campos, e da Jovem Pan, em Itaperuna. O número de FMs suplanta o de emissoras AM e há um número considerável de rádios comunitárias entre as contabilizadas no Gráfico 1. Muitas delas estão sob gestão de grupos religiosos.

Com relação à web, a presença dos veículos de comunicação do interior fluminense na Internet é massiva, mas não obedece a um padrão. Encontramos desde os blogs criados em plataformas gratuitas, com design mais simples, funcionando apenas para agregar conteúdo sobre a região ou simplesmente para garantir maior alcance à transmissão da programação da rádio, até os sites mais sofisticados que oferecem atualização dinâmica de notícias, arquivo de edições anteriores, enquetes, áudio e vídeo, acesso a outros portais, interatividade em tempo real e veiculação de publicidade, passando pelos links de grandes portais dedicados à cobertura de determinadas regiões (R7, da Rede Record, e G1, das Organizações Globo).

Os portais, sites e blogs de notícias que funcionam como empresas autônomas, ou seja, têm produção própria de notícias e receita publicitária sem vinculação com outras mídias, caracterizam-se, salvo raras exceções, por serem micro e pequenas empresas; pela inexperiência dos gestores no mundo dos negócios e pela arrecadação relativamente baixa, vinda exclusivamente dos anunciantes, uma vez que o acesso ao site é sempre gratuito para o leitor.

Com relação à presença nas redes sociais, quase a totalidade desses veículos tem um perfil no Facebook ou uma conta no Twitter, mas a frequência do uso dessas ferramentas com a finalidade de distribuir conteúdo e interagir com o público segue modelos diversos. É comum encontrarmos contas abandonadas há mais de um ano; contas com postagens com semanas e até meses de espaçamento; contas ativas, mas que não permitem interação e comentários, e contas muito ativas, cujo conteúdo interativo costuma influenciar o conteúdo das plataformas tradicionais dessas mídias.

Durante nossa pesquisa de campo, observamos que a localização geográfica, o mercado local e a área de atuação da empresa jornalística podem interferir diretamente em sua arrecadação. O contexto geográfico e o contexto econômico, aliás, são reconhecidos pelos gestores como variáveis importantes para os negócios e também para o conteúdo das notícias. Outra variável que implica diretamente a posição da empresa de mídia no mercado é o investimento em inovações tecnológicas. Para os gestores de médias e grandes empresas de mídia localizadas no interior fluminense isso parece ser especialmente determinante. Apenas os gestores de pequenas empresas que atuam em cidades onde não há concorrência significativa julgam que investir em tecnologia não interfere em sua competitividade.

A respeito dos consumidores de notícias, temos verificado que existe um interesse elevado por parte dos moradores das cidades do interior fluminense por notícias locais e regionais, conforme o Gráfico 2, extraído dos resultados de uma investigação que realizamos, ${ }^{13}$ em que 1 é pouco interessado e 5, muito interessado.

13 Embora nossa tese não contemple uma análise das audiências da mídia do interior fluminense, realizamos uma pesquisa on-line em dezembro de 2013, com caráter exploratório, para tentar identificar a opinião dos consumidores de notícias locais e regionais a respeito dos produtos disponíveis no mercado. 0 objetivo foi reunir elementos para as entrevistas que temos feito com os gestores dessas mídias e que vêm a ser nossa principal ferramenta de coleta de dados. As considerações desses dois últimos parágrafos da seção sintetizam o resultado do e-survey, que contou com 181 participantes de 42 cidades do interior fluminense. 0 questionário pode ser consultado em <https://docs.google.com/forms/d/1LKIBkq093fbxygkXH76BgxFdloUo 7HXbqKhGCK34_jw/viewform >. Os resultados gerais permanecem inéditos. 
GRÁFICO 2

Nível de interesse das audiências por notícias locais e regionais

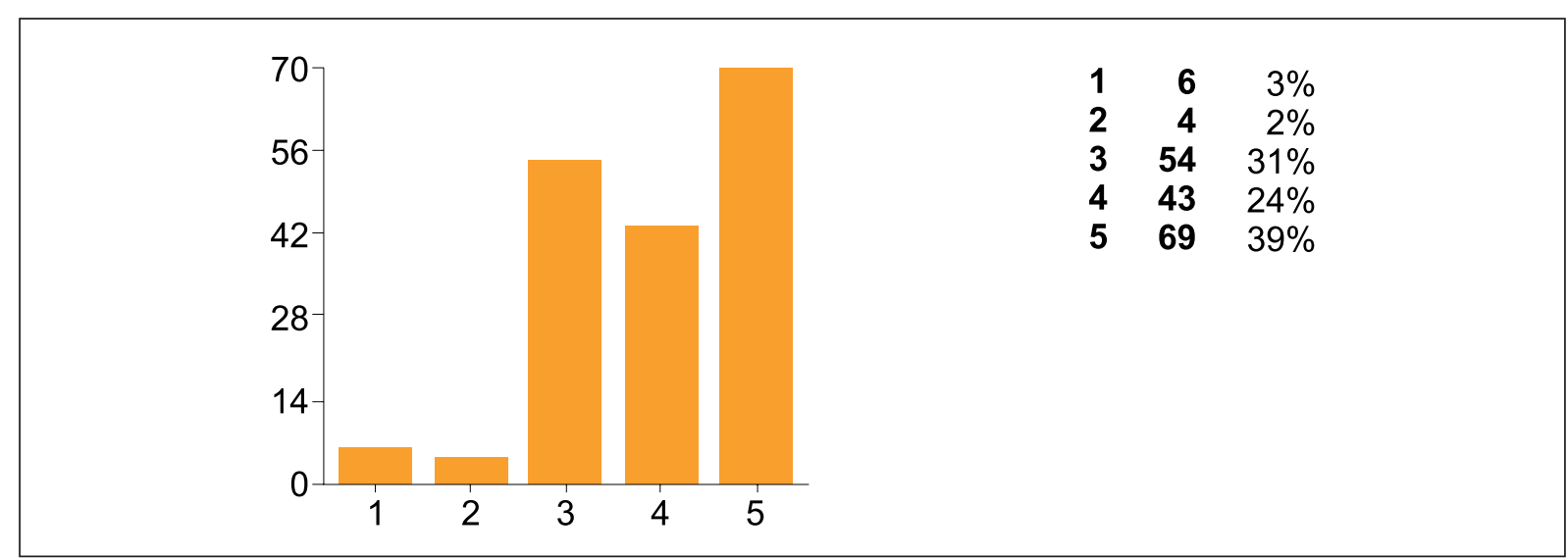

Fonte: Elaboração própria.

Para muitos deles, saber o que se passa em sua cidade e no entorno é considerado importante para a socialização, a prática da cidadania e para respaldar desde as decisões cotidianas até as relacionadas a eventos importantes para a própria vida ou para o andamento da sociedade. No entanto, uma parcela importante das audiências reclama da qualidade do jornalismo praticado no interior fluminense e quer uma mídia regional mais independente e autônoma, mais próxima do público, mais dialógica, mais dedicada ao jornalismo de serviço, mais profissional.

Para muitos moradores do interior fluminense usuários de internet, os meios digitais, principalmente as redes sociais, são plataformas úteis para obter notícias, além de amigáveis e favoráveis ao debate a respeito do lugar onde vive e a mídia opera. No entanto, eles julgam que esse potencial é subestimado pelos donos dos meios de comunicação.

\section{3 - Jornalismo local e regional: função e valor}

Partimos da assunção de que o jornalismo é uma atividade de natureza dual. Enquanto firma necessita, como qualquer outra, de ser sustentável, quiçá lucrativa, e a falta de recursos financeiros pode resultar em diversas limitações operacionais, como, por exemplo, restringir a atuação das equipes de reportagem dentro de sua área de cobertura ou, ainda, forçar a empresa a realizar parcerias e associações que podem acabar por comprometer sua independência editorial. Por outro lado, configura-se como um serviço público, dotado de uma função social que é atender as demandas do público-cidadão por informações que lhes permitam decidir sobre a própria vida e a vida em sociedade. Além disso, a estreita relação entre comunicação e poder não raro se reflete sobre a política de funcionamento das empresas jornalísticas, sua estrutura, linha editorial, abrangência e conteúdo.

Por causa de todos esses constrangimentos é que, muitas vezes, pesam sobre essas companhias demandas insatisfeitas, críticas e descréditos por parte de audiências que se consideram não representadas ou não atendidas por essa função social, em geral abordada com muito mais ênfase tanto pelo público quanto pela Academia, ainda que sua dimensão econômica deva ser considerada como parte importante da explicação dos seus modos de operar. Obviamente, não se trata de justificar os maus desempenhos da mídia, mas de chamar atenção para aspectos que são fundamentais para o debate a respeito da relação que os meios de comunicação podem estabelecer com os lugares em que estão sediados e com sua região. 
No interior do Estado do Rio, pelo que se pode extrair da avaliação do público participante da pesquisa mencionada ao final da seção anterior, tanto as mídias mais favorecidas economicamente quanto aquelas que operam de modo mais elementar ou sem a intenção de lucro terão um valor superior para suas audiências e, consequentemente, para a sociedade como um todo se 1) investirem ainda mais em notícias locais e reportagens de serviço e 2) promoverem uma vinculação mais estreita com seus públicos, inclusive abrindo espaço para o jornalismo participativo, conforme indicam alguns dos comentários recolhidos durante a pesquisa quando perguntamos "O que a mídia de sua cidade poderia fazer para se tornar ainda melhor e mais útil para os cidadãos?”:

"Ter profissionais qualificados."

"Ser mais crítica em relação aos problemas da cidade."

"Caminhar com suas próprias pernas e deixar de ser subserviente de contas publicitárias oficiais."

"Ser mais rápida ao noticiar, e não esconder notícias pq estas não agradam a determinadas esferas da sociedade."

"Fazer mais matérias sobre as necessidades dos bairros."

"Existir!!!"

"Noticias mais atualizadas, informações construtivas, menos euforia com as noticias da prefeitura."

"Aumentar a qualidade das reportagens."

"Se dedicar mais".

"Especializar-se."

"Divulgar mais as notícias de interesse do cidadão, como serviços gratuitos, cultura, cursos, empregos e até orientação de como reclamar seus direitos”.

"Acredito que investir mais em serviços do que em tragédias, além de oferecer mais recursos aos funcionários, o que resultaria em um trabalho melhor. Logo, o leitor/público/ouvinte teria informação de mais qualidade e precisão.”

"Interagir com os outros meios de comunicação".

"Ser mais profissional, em todos os sentidos. Investir mais em infraestrutura, em profissionais (melhores salários) e estar mais envolvida com as novas tecnologias.”

"Um horário na tv aberta com reportes nas ruas perguntando sobre a opnião publica de assuntos diversos e mudanças decorrentes.”

“Tornar as reportagens mais atrativas, melhorar divulgação online das mesmas.”

"Criar uma pauta com conteúdo mais diversificado”.

"Descentralizar-se (maior liberdade e espaço para que mais cidadãos publicassem em um meio de comunicação o que veem acontecer em seus bairros)". ${ }^{14}$

Para Robert G. Picard (2013), tais mudanças de postura são condição, inclusive, para a 
sobrevivência das empresas jornalísticas. O autor entende que o jornalismo contemporâneo passa por um momento de crise, tanto pelas demandas que não consegue suprir quanto pelo consequente esvaziamento de público e de arrecadação, e precisa, ao mesmo tempo, garantir receitas e redescobrir seu papel nas sociedades democráticas. Os desafios são 1) atender os desejos e necessidades de um público cada vez mais exigente e 2) criar valor para essas audiências, tornando-se relevante e imprescindível para elas. Sob o ponto de vista do autor, o livro-caixa se veria consequentemente mais movimentado porque mais pessoas despertarão interesse pelo conteúdo da mídia e também porque mais anunciantes se interessarão em financiá-la para ter acesso aos membros dessa audiência crescente.

Se, de fato, "o valor é criado pelos produtos noticiosos que informam, entretêm e estimulam, mas também pelo conhecimento e compreensão que auxiliam nas tomadas de decisão e na resolução de desafios” (PICARD, op. cit., p. 72), configura-se, aí, um terceiro desafio para as empresas jornalísticas locais e regionais: investir em um quadro composto de pessoas comprometidas e competentes para realizarem um trabalho social de alta importância e produzir um conteúdo capaz de suprir as demandas dos membros das comunidades por notícias, informação, interpretações e pontos de vista, auxiliando-os nas tomadas de decisão, encorajando-os e apresentando-lhes opções.

\section{Últimas considerações}

Neste texto, procuramos traçar um perfil da mídia do interior fluminense a partir da distribuição das empresas jornalísticas pelas regiões de governo, de algumas características gerais da organização do setor, de aspectos da sustentabilidade econômica dessas companhias e da opinião das audiências sobre a qualidade do serviço oferecido pelas mídias locais e regionais. Nossas considerações têm como base os dados que temos coletado ao longo de nossa pesquisa de campo e o acompanhamento que temos feito do comportamento dessas firmas em sua área de atuação.

Na tentativa de sintetizar algumas de nossas observações, podemos citar que, no caso da mídia em funcionamento no interior do Estado do Rio de Janeiro,

1) há uma relevante concentração espacial de serviços de mídia de mais alta ordem em poucos centros regionais com características demográficas e econômicas mais complexas;

2) não raro os meios de comunicação maiores e/ou mais consolidados estão em cidades onde já existe uma tradição de produção midiática, o que indica a relevância dos hábitos culturais e de consumo da população para atrair e justificar a presença desse tipo de serviço;

3) os impressos, as emissoras de rádio e TV e os sites de notícias, em geral, realizam uma produção de notícias bastante localizada na cidade em que a mídia está sediada, não atendendo todas as demandas do entorno ou de sua área de cobertura, por diversos motivos. Por isso, não raro trabalham com uma área de mercado bastante restrita, embora com possibilidade de ampliação;

4) tem crescido a importância das plataformas on-line para a produção jornalística local, entre outros motivos, como uma estratégia para suprir a demanda por notícias 
em lugares onde os meios de comunicação que se intitulam regionais não chegam. No entanto, a sustentabilidade financeira dos sites, salvo poucas exceções, ainda é frágil;

5) A produção de notícias locais tem uma reserva potencial ainda não explorada.

Justamente por causa da abordagem restrita deste trabalho, acreditamos que o artigo deixa descobertas algumas lacunas importantes, e aqui citamos quatro, que pretendemos preencher a seu tempo.

A primeira é um estudo mais minucioso da correspondência entre a localização das empresas de mídia e o capital cultural, humano e criativo presente nas cidades em que elas estão sediadas. Sabemos, por exemplo, que as cidades do interior fluminense que têm negócios de mídia mais consolidados e funcionando em diversas plataformas (on-line, impressa e eletrônica) têm também faculdades de publicidade e propaganda, jornalismo e design a fornecer profissionais qualificados para o mercado de trabalho. Analisar como a associação de empreendedores desse setor e de setores afins favorece a formação de clusters (Pratt, 2007), retroalimenta a indústria de mídia (Silva, 2010) e ajuda a fortalecer a vocação do lugar como território midiático (Deolindo e Moreira, 2013) pode ampliar nossa compreensão a respeito das condições de funcionamento desse mercado específico.

A segunda é o papel das empresas de mídia na rede urbana. Em outra ocasião (Deolindo, 2014a), defendemos a importância de um estudo dedicado a compreender o papel dessas firmas nos diversos tipos de cidades e do mapeando dos fluxos que os meios de comunicação põem em circulação ao ampliarem as escalas do trânsito de ideias e mercadorias. Nossa hipótese é de que, por tudo isso, a mídia pode afetar a complexidade dos lugares e a dimensão espacial da formação econômico-social, produzindo, reproduzindo e ressignificando espacialidades.

Estudos avançados sobre a rede formada por "cidades de mídia", com foco sobre as maiores metrópoles internacionais, já vêm sendo desenvolvidos desde o início dos anos 2000 por pesquisadores do Globalization and World Cities (GaWC) Research Network ${ }^{15}$ (Krätke, 2003; Krätke e Taylor, 2004; Hoyler e Watson, 2013; Mould, 2014). Entretanto, permanece uma lacuna referente à escala local e regional. Até onde nos consta, no Brasil, essa abordagem permanece inexplorada.

A terceira é uma avaliação do nível de desenvolvimento da mídia local e regional, que, na verdade, deve ser entendido para além do tamanho da empresa, da saúde das finanças, do profissionalismo, da tecnologia adotada, da sofisticação dos produtos postos em circulação e do seu poder de influência. Seguindo a perspectiva da Unesco (2010), os indicadores de desenvolvimento da mídia são seu compromisso com o livre fluxo e acesso à informação, com a liberdade de expressão, com a independência editorial, com o pluralismo de vozes e com a promoção da democracia, ou seja, com o desenvolvimento das comunidades no sentido mais amplo do termo.

A quarta, relacionada a esta, é justamente a necessária reflexão sobre o papel das empresas de mídia no desenvolvimento local e regional. Não há uma profusão de estudos sobre o tema tendo como foco o Estado do Rio de Janeiro, mas um trabalho importante vem sendo desenvolvido pela colega Karla Ribeiro Marinho, que investiga como o uso das novas tecnologias da comunicação e da informação tem colaborado com o empoderamento das comunidades rurais do interior fluminense e, por consequência, com a transformação qualitativa do território. ${ }^{16}$ 
De nossa parte, acreditamos que o artigo que apresentamos, ainda que breve, pode ser considerado uma primeira contribuição para dar a conhecer aspectos importantes da produção midiática no interior fluminense. Como já apontamos (Deolindo, 2013), o tema tem sido negligenciado pelas pesquisas da área de Comunicação em nível de pós-graduação stricto sensu, já que as dissertações e teses defendidas nas instituições fluminenses sobre a mídia no Estado em geral se ocupam dos fenômenos midiáticos localizados na capital e na Região Metropolitana.

Entretanto, é importante dedicar um olhar atento a essa periferia geográfica e simbólica porque ela, atualmente, tanto encerra complexidades e produz influências que contrariam as interpretações correntes de "interior" quanto também registra carências que relegam seus moradores às mais duras realidades, geradas, inclusive, pela a escassez de informação.

\section{Referências bibliográficas}

ABERT (Associação Brasileira de Rádio e Televisão). Tudo o que você precisa saber sobre rádio e televisão, licenças, outorgas, taxa de penetração, receitas e receptores. Brasília, 2013. Disponível em <http://www.abert.org.br/web/index.php/bibliotecas/2013-05-22-13-32-13/ item/tudo-o-que-voce-precisa-saber-sobre-radio-e-televisao-licencas-outorgas-taxa-depenetracao-receitas-e-receptores > . Acesso em 26 de julho de 2014.

ABTA (Associação Brasileira de TV por Assinatura). Dados do setor. [On-line] São Paulo, 2013. Disponível em <http://www.abta.org.br/dados_do_setor.asp>. Acesso em 28 de julho de 2014. ANCINE (Agência Nacional de Cinema). Mapeamento da TV Aberta. Rio de Janeiro, 2011. Disponível em <http://www.ancine.gov.br/media/SAM/Estudos/Mapeamento_TVAberta_ Publicacao.pdf $>$. Acesso em 28 de julho de 2014

ANJ (Associação Nacional de Jornais). Cenário [2014, on-line]. Disponível em http://anj.org. br/cenario. Último acesso em 22 de novembro de 2014

DEOLINDO, Jacqueline da Silva. Geoeconomia da mídia regional: produção midiática no interior fluminense. In: $6^{\circ}$ CONGRESSO DE ESTUDANTES DE PÓS-GRADUAÇÃO EM COMUNICAÇÃO. Rio de Janeiro, 2013. Rio de Janeiro: UERJ, 2013. Disponível em http:// www.coneco.uff.br/sites/default/files/institucional/geoeconomia_da_midia_regional.pdf. Acesso em 31 de outubro de 2014.

. Contribuição da teoria das localidades centrais para o estudo da mídia no espaço. In: $37^{\circ}$ CONGRESSO DE CIÊNCIAS DA COMUNICAÇÃO, Foz do Iguaçu, 2014. Anais. São Paulo: Intercom, 2014a [on-line]. Disponível em http://www.intercom.org.br/papers/nacionais/2014/ resumos/R9-2115-1.pdf. Acesso em 31 de outubro de 2014.

. Brazilian Media industries: Elements for an economic/ geographic study. In: 11th WORLD MEDIA ECONOMICS \& MANAGEMENT CONFERENCE. 2014. Anais. Rio de Janeiro: UERJ, 2014b. (PDF em mídia digital)

DEOLINDO, Jacqueline da Silva; MOREIRA, Sonia Virgínia. Notas para um estudo geoeconômico da indústria brasileira de mídia. Revista Tríade - Comunicação, cultura e mídia, vol. 2, n. 3, 2014. Disponível em http://periodicos.uniso.br/ojs/index.php?journal=tri ade\&page $=$ article\&op $=$ view\&path\%5B\%5D=1899\&path\%5B\%5D=1716. Último acesso em 31 de outubro de 2014 
DUARTE, Ronaldo Goulart. Aspectos da geoeconomia Fluminense. Revista Eletrônica do Vestibular, Ano 2, n. 3, 2009. Disponível em http://www.revista.vestibular.uerj.br/artigo/ artigo-pdf.php?seq_artigo=5. Acesso em 31 de outubro de 2014.

EMPRESA BRASILEIRA DE COMUNICAÇÃO (EBC). Aumento do acesso às redes sociais multiplica o número de "produtores de notícia". Brasília: Portal EBC, 2013. Disponível em <http://www.ebc.com.br/tecnologia/2013/05/aumento-do-acesso-as-redessociais-multiplicanumero-de-produtores-de-noticia >. Acesso em 31 de outubro de 2014.

FUNDAÇÃO CEPERJ. Anuário Estatístico do Estado do Rio 2013 [2014a, on-line]. Disponível em http://www.ceperj.rj.gov.br/ceep/Anuario2013/index.html. Acesso em 31 de outubro de 2014.

. Estado do Rio de Janeiro - Regiões de Governo [2014b, on-line]. Disponível em http:// www.ceperj.rj.gov.br/ceep/info_territorios/divis_regional.html. Acesso em 31 de outubro de 2014.

. Mapa da Região Metropolitana do Rio de Janeiro. [2014c, on-line]. Disponível em http://www.ceperj.rj.gov.br/ceep/info_territorios/RMRJ2013.pdf. Acesso em 31 de outubro de 2014.

FUSCO, Fabrício Marini. Nem no céu, nem na terra: reflexões sobre a relação rural/urbano no Estado do Rio de Janeiro. In: MARAFON, Gláucio José; RIBEIRO, Miguel Angelo. (orgs.). Revisitando o Território Fluminense II. Rio de Janeiro: Gramma, 2008.

HOYLER, Michael; WATSON, Allan. Global Media Cities in Transnational Media Networks. Tijdschrift voor Economische en Sociale Geografie, vol. 104, n. 1, pp. 90-108, 2013.

IBGE (Instituto Brasileiro de Geografia e Estatística). Regiões de Influência das Cidades. Rio de Janeiro, 2008.

. Rio de Janeiro. [2014, on-line]. Disponível em http://cidades.ibge.gov.br/download/ mapa_e_municipios.php?lang=\&uf=rj. Acesso em 31 de outubro de 2014.

IVC (Instituto Verificador de Circulação). Estudo sobre audiência de websites - Base IVC: Jan 2011-Dez 2012 [2013, on-line]. Disponível em http://www.ivcbrasil.org.br/conteudos/ pesquisas_estudos/AudienciaWeb2012.pdf. Acesso em 31 de outubro de 2014.

KRÄTKE, Stefan. Global Media Cities in a Worldwide Urban Network. European Planning Studies, vol. 11, n. 6, pp. 605-628, 2003.

KRÄTKE, Stefan; TAYLOR, Peter. A World Geography of Global Media Cities. European Planning Studies, vol. 12, n. 4, pp. 459-477, 2004.

MARINHO, Karla Azeredo Ribeiro. Comunicação e desenvolvimento local: TIC's e a reorganização produtiva do Uruguai rural. In: 37 CONGRESSO DE CIÊNCIAS DA COMUNICAÇÃO, Foz do Iguaçu, 2014. Anais Intercom [on-line]. Disponível em http://www. intercom.org.br/papers/nacionais/2014/resumos/R9-2093-1.pdf. Acesso em 31 de outubro de 2014.

MOREIRA, Sonia Virgínia. (org.). Geografias da Comunicação: espaço de observação de mídia e de culturas. São Paulo: Intercom, 2013.

MOULD, Oli. Mediating the City: The Role of Planned Media Cities in the Geographies of Creative Industry Activity. In: CONVENTZ at al. (eds.). Hub Cities in the Knowledge Economy: Seaports, Airports, Brainports. Farnham: Ashgate, 2014. pp. 163-180.

NOAM, Eli. Media conglomerates around the work. In: 11th WORLD MEDIA ECONOMICS 
AND MANAGEMENT CONFERENCE (Notas de conferência). Rio de Janeiro: Universidade do Estado do Rio de Janeiro, 2014.

PICARD, Robert G. Criação de valor e o future das organizações jornalísticas - Por que motivo e como o jornalismo deve mudar para se manter relevante no século XXI. Porto: Editora Media XXI, 2013.

PRATT, Andy C. An economic geography of the cultural industries. London: LSE Research Online, 2007. [On-line] Disponível em: <http//: e-prints.lse.ac.uk/855>. Acesso em 28 de julho de 2014.

RIBEIRO, Miguel Angelo; CAVALCANTI, Vera Maria d’Ávila. Tipologia urbana: o exemplo do estado do Rio de Janeiro. In: PACHECO, Susana Mara; MACHADO, Monica Sampaio. Globalização, políticas públicas e reestruturação territorial. Rio de Janeiro: Editora 7 Letras, 2012.

SANTOS, Milton. Classificação funcional dos jornais brasileiros - As regiões jornalísticas (1955). Noticiários da Rede Alcar. Ano 7, n. 83, Nov., 2007. Disponível em <http://www2. metodista. br/unesco/rede_alcar/Rede_Alcar_83/serie_imprensa.htm>. Acesso em 31 de outubro de 2014.

SILVA, João Luiz de Figueiredo. A emergência da geografia econômica das indústrias culturais. Geo UERJ, Ano 12, vol. 1, n. 21, $1^{\circ}$ sem. 2010. Disponível em <www.geouerj.uerj.br/ojs>. Acesso em 27 de julho de 2014.

SILVA, Robson Dias da. Estrutura industrial e desenvolvimento regional no Estado do Rio de Janeiro (1990-2008). Tese de doutorado. Instituto de Economia da Universidade Estadual de Campinas, 2009. Disponível em <http://www.bibliotecadigital.unicamp.br/ document/?code=000480270 > . Acesso em 28 de julho de 2014.

UNESCO (Organização das Nações Unidas para a Educação, a Ciência e a Cultura). Indicadores de desenvolvimento da mídia: marco para a avaliação do desenvolvimento dos meios de comunicação. Brasília, 2010. 
